\title{
TPHA test
}

\section{Experience at the Clinic of Dermatology, University of Milan}

\author{
E. ALESSI AND L. SCIOCCATI \\ From the Clinic of Dermatology of the University of Milan
}

SUMMARY The results of serological investigations with the treponemal haemagglutination (TPHA) test are reported in a large number of luetic and non-luetic patients. From these the following conclusions can be drawn: (1) The sensitivity of the TPHA test is decreased if the test is carried out with micromethods; however, in our opinion, the same degree of sensitivity can be obtained either with the macromethod at dilution $1 / 80-1 / 60$ or with micromethods at $1 / 20-1 / 40$. (2) The sensitivity of this test is high, being similar to that of the fluorescent treponemal antibody absorption (FTA-ABS) test in primary and secondary syphilis and even higher than that of the FTA-ABS test in treated subjects. (3) The specificity of the reaction is high, as demonstrated by examining sera in patients with a negative history and clinical examination together with negative results to Treponema pallidum immobilisation (TPI) and FTA-ABS tests, and by studying biological false positive sera. (4) For the serological screening, it may be sufficient to perform the TPHA test with the 1/20-1/40 micromethod together with the Venereal Disease Research Laboratory (VDRL) test. In patients with suspected syphilis, it is advisable to perform the TPHA test by the macromethod, in combination with the FTA-ABS test.

\section{Introduction}

The treponemal haemagglutination (TPHA) test has been studied for several years at our institute and it is now used routinely for detecting antitreponemal antibodies in patients attending the Centro Antivenero (Center for Venereal Diseases) of the University of Milan.

The characteristics of this reaction are well known (Rathlev, 1967; Tringali, 1970; Coffey et al., 1972; Garner et al., 1972; Johnston, 1972; Luger and Spendlingwimmer, 1973; Young et al., 1974; O'Neill, 1976). We should like to add our contribution, based on personal experience. Technical details are given in previous papers (Alessi $e t$ al., 1973; Alessi and Scioccati, 1977).

\section{Methods}

The manual macromethod traditionally used for the TPHA test has recently started to be replaced

Address for reprints: E. Alessi, Clinic of Dermatology, University of Milan, Milan, Italy

Received for publication 8 July 1977 by micromethods because of the high cost of reagents and the need to automate the reaction in mass serological screening.

However, the data indirectly show that the sensitivity of the reaction is adversely affected by these modifications. Indeed, while those who use macromethods (Rathlev, 1967; Tringali, 1970; Luger and Spendlingwimmer, 1973) report reactivity early in the course of infection (as with the fluorescent treponemal antibody absorption (FTA-ABS) test), those who use micromethods (Coffey et al., 1972; Garner et al., 1972; Johnston, 1972; Young et al., 1974) observe delayed reactivity, which in some cases occurs only at the beginning of the secondary stage.

These different findings can be accounted for by comparing the results of macromethods with those of micromethods on 479 sera* (Alessi and Scioccati, 1977) (Tables 1 and 2). Our investigation showed that with the same serum dilutions the micromethod was less sensitive than the macromethod. We therefore prefer the macromethod, not only for studying the characteristics of the reaction but also

*Reagents from Fujizoki Pharmaceutical Co. Tokyo 
Table 1 Positive TPHA reactions in patients with primary and secondary syphilis (180 cases)

\begin{tabular}{|c|c|c|c|}
\hline \multicolumn{2}{|c|}{ Micromethod } & \multicolumn{2}{|c|}{ Macromethod } \\
\hline Dilution & $\%$ & Dilution & $\%$ \\
\hline $\begin{array}{l}1 / 20 \\
1 / 40 \\
1 / 80 \\
1 / 160\end{array}$ & $\begin{array}{l}91 \cdot 1 \\
88 \cdot 3 \\
74 \cdot 4 \\
67 \cdot 2\end{array}$ & $\begin{array}{l}1 / 80 \\
1 / 160\end{array}$ & $\begin{array}{l}91 \cdot 6 \\
83 \cdot 8\end{array}$ \\
\hline
\end{tabular}

Table 2 Positive TPHA reactions in patients with treated primary and secondary syphilis (299 cases)

\begin{tabular}{lllll}
\hline \multicolumn{2}{l}{ Micromethod } & & & \multicolumn{2}{l}{ Macromethod } \\
\cline { 5 - 5 } Dilution & $\%$ & & Dilution & $\%$ \\
\hline $1 / 20$ & 94.9 & & \\
$1 / 40$ & 91.6 & & $1 / 80$ & 94.9 \\
$1 / 80$ & 83.9 & & & \\
$1 / 160$ & 66.5 & & \\
\hline
\end{tabular}

for obtaining firm evidence in dubious cases; therefore we used the macromethod in our research. However, should it be necessary to resort to a micromethod-such as, for mass serological screening-we would use it at $1 / 20-1 / 40$ serum dilutions, although these dilutions give a slightly higher number of false positive reactions and spontaneous haemagglutinations. As shown in Tables 1 and 2, the percentage of positive reactions obtained with the micromethod at the lowest dilutions is practically the same as that obtained with the macromethod at dilutions of $1 / 80-1 / 160$.

\section{Results and discussion}

SENSITIVITY

We found that in the early stage of syphilis the sensitivity of the TPHA test was similar to that of the FTA-ABS test, the percentages of positive reactions found in the different groups of sera examined being practically identical.

Of 90 cases of untreated primary syphilis confirmed by darkfield examination (Table 3), we obtained $83.3 \%$ positive reactions with TPHA $(1 / 80)$ and $81 \cdot 1 \%$ positive reactions with FTA-ABS. In 90 cases of untreated secondary syphilis, all the sera were found to be positive with both reactions.

It also seemed worthwhile to study the relationship of time of the reactivity and compare it with other serological tests. Patients were divided into three groups according to date of infection (Table 4). It was observed that haemagglutinating antibodies appeared early; over $70 \%$ of the cases had positive results within 30 days of the infectious sexual intercourse (this percentage was the highest of all the reactions examined). A second study of antibody titres carried out on a few positive sera (Table 5) revealed that the reaction was positive up to a dilution of 1 in 10240 at the primary stage of the infection, and up to a dilution of 1 in 655360 at the secondary stage.

The TPHA test remains positive for a long time, even in treated subjects. An investigation on 228 sera of patients with syphilis detected either at the primary or the secondary stage and examined one to 10 years after completion of treatment (Table 6) showed a higher percentage of positive reactions than with any other test, including FTA-ABS. We even found several positive reactions in patients who had acquired the infection 20 to 30 years before the serological tests.

Table 3 Positive serological reactions ( $\%$ ) in primary and secondary syphilis

\begin{tabular}{llc}
\hline & $\begin{array}{l}\text { Primary syphilis } \\
(90 \text { cases })\end{array}$ & $\begin{array}{l}\text { Secondary syphilis } \\
(90 \text { cases })\end{array}$ \\
RPCF & $57 \cdot 7$ & $95 \cdot 5$ \\
VDRL & $62 \cdot 2$ & 100 \\
TPI & $28 \cdot 8^{*}$ & $95 \cdot 5 \dagger$ \\
FTA-ABS & $81 \cdot 1$ & 100 \\
TPHA 1/80 & $83 \cdot 3$ & 100 \\
\hline
\end{tabular}

*Doubtful TPI test in another $16.6 \%$ of cases

†Doubtful TPI test in another $3 \cdot 3 \%$ of cases

Table 4 Positive serological reactions (\%) in primary and secondary syphilis according to date of infection

\begin{tabular}{llll}
\hline \multicolumn{4}{c}{ Days from infection } \\
\cline { 2 - 4 } & $<30$ & $30-40$ & $>40$ \\
& $(35$ cases $)$ & $(31$ cases $)$ & $(24$ cases $)$ \\
RPCF & $31 \cdot 7$ & $32 \cdot 2$ & $95 \cdot 8$ \\
VDRL & 40 & $67 \cdot 7$ & $95 \cdot 8$ \\
TPI & $5 \cdot 7 *$ & $38 \cdot 7 \dagger$ & $54 \cdot 1 \ddagger$ \\
FTA-ABS & $62 \cdot 8$ & 87 & 100 \\
TPHA 1/80 & $71 \cdot 4$ & 80 & 100 \\
\hline
\end{tabular}

*Doubtful TPI in another $8.5 \%$ of cases

†Doubtful TPI in another $16.1 \%$ of cases

‡Doubtful TPI in another $33.3 \%$ of cases

Table 5 Positive TPHA reactions (\%) at the different dilutions in positive sera of patients with primary and secondary syphilis

\begin{tabular}{lrlr}
\hline $\begin{array}{l}\text { Primary syphilis } \\
\text { (32 cases) }\end{array}$ & \multicolumn{3}{l}{$\begin{array}{l}\text { Secondary syphilis } \\
(20 \text { cases })\end{array}$} \\
\hline $1 / 80$ & 100 & $1 / 320$ & 100 \\
$1 / 160$ & 78 & $1 / 5120$ & 95 \\
$1 / 320$ & 53 & $1 / 10240$ & 75 \\
$1 / 640$ & 44 & $1 / 20480$ & 60 \\
$1 / 1280$ & 25 & $1 / 40960$ & 45 \\
$1 / 2560$ & 12 & $1 / 81920$ & 35 \\
$1 / 5120$ & 9 & $1 / 163840$ & 15 \\
$1 / 10240$ & 3 & $1 / 655360$ & 10 \\
\hline
\end{tabular}


Table 6 Positive serological reactions in subjects with treated primary or secondary syphilis (tests performed 1 to 10 years after the end of treatment )

\begin{tabular}{llc}
\hline & \multicolumn{2}{l}{ Percentage of treated syphilis } \\
\cline { 2 - 3 } & $\begin{array}{l}\text { Primary } \\
(113 \text { cases })\end{array}$ & $\begin{array}{c}\text { Secondary } \\
(115 \text { cases })\end{array}$ \\
\hline RPCF & $0 \cdot 8$ & $4 \cdot 3$ \\
VDRL & $6 \cdot 1$ & $12 \cdot 1$ \\
TPI & $12 \cdot 3^{*}$ & $36 \cdot 5 \dagger$ \\
FTA-ABS & $71 \cdot 6$ & $98 \cdot 2$ \\
TPHA 1/80 & $88 \cdot 4$ & $100 \cdot 0$ \\
\hline
\end{tabular}

*Doubtful TPI in another $18.5 \%$ of cases

†Doubtful TPI in another $20.0 \%$ of cases

\section{SPECIFICITY}

The treponemal haemagglutination reaction is attributed an extremely high specificity (Cox et al., 1969; Tringali, 1970; Young et al., 1974), comparable with that of the Treponema pallidum immobilisation (TPI) and FTA-ABS tests, although there are authors who question this (Garner et al., 1973). Our experiments were on 559 patients (Table 7), who were in hospital because of various dermatoses-such as psoriasis, contact dermatitis, tumours, or tinea pedis. All patients were free from clinical symptoms of syphilis, the disease also being absent from their personal and family history. In a first group of 324 sera which gave negative Reiter protein complement fixation (RPCF), VDRL, and TPI reactions, nine $(2.79 \%)$ were found to be TPHA positive. In another group of 235 sera, giving not only negative RPCF, VDRL, and TPI reactions but also a negative FTA-ABS reaction, one $(0.4 \%)$ was TPHA positive. A comparison between the two groups clearly shows that, if a negative TPI result is regarded as sufficient to rule out the presence of syphilis, the percentage of false positive TPHA tests appears to be high; on the other hand, if a negative FTA-ABS test is also regarded as being necessary for syphilis to be ruled out, then that percentage is reduced to acceptable values.

We also examined 50 sera with positive VDRL and/or RPCF reactions and negative TPI and FTA-ABS results (Table 7). In this third group of sera, $4 \%$ of the patients were TPHA positive, as

Table 7 Positive TPHA reactions in clinically negative subjects (609 cases)

\begin{tabular}{lc}
\hline Group & $\%$ \\
\hline $\begin{array}{l}\text { First (324 cases) } \\
\text { (RPCF, VDRL, and TPI negative subjects) }\end{array}$ & 2.79 \\
$\begin{array}{l}\text { Second (2.35 cases) } \\
\text { (RPCF, VDRL, TPI, and FTA-ABS negative subjects) }\end{array}$ & 0.4 \\
$\begin{array}{l}\text { Third (50 cases) } \\
\text { (RPCF and/or VDRL positive but TPI and FTA-ABS } \\
\text { negative subjects) }\end{array}$ & 4.0 \\
\hline
\end{tabular}

two VDRL positive sera were also found to be TPHA positive, probably owing to biological false positive results.

The problem of specificity is a difficult one as the patient's history is often unreliable, and the extremely high sensitivity of the reaction may cause positive reactions occasionally to be found many years after the infection when all other serological tests have become negative. Consequently, there are no reliable criteria for regarding a single positive TPHA result as non-specific.

\section{Conclusion}

In clinical practice the TPHA test is useful for serological screening, in combination with the VDRL reaction. In this case, because it is cheap, the micromethod at serum dilutions of $1 / 20-1 / 40$ should be chosen and results evaluated as shown in Fig. 1.

It is also useful for diagnostic purposes, in patients with doubtful clinical history, symptoms, and serological results. In this case, the macromethod should be used as the higher dilution of sera reduces the incidence of inconclusive results caused by spontaneous haemagglutination in controls. It also reduces the incidence of false positive reactions. In this case, results will be evaluated in accordance with the scheme illustrated (Fig. 2).

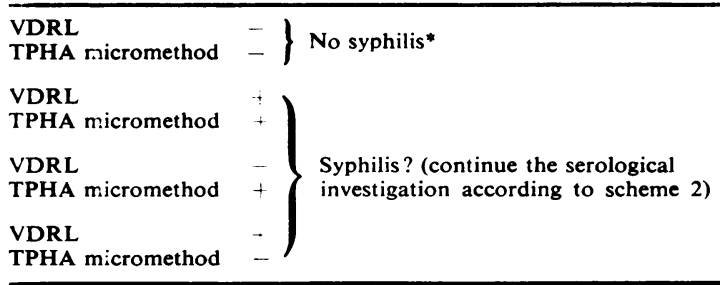

*The term 'no syphilis' is adopted for practical screening purposes only, since zyphilis at a very early stage or long-since treated syphilis cannot be ruled out

Fig. 1 Scheme for the serological screening

\begin{tabular}{|c|c|}
\hline $\begin{array}{l}\text { FTA-ABS } \\
\text { TPHA macromethod }\end{array}$ & $\begin{array}{l}- \\
-\end{array}$ No syphilis \\
\hline $\begin{array}{l}\text { FTA-ABS } \\
\text { TPHA macromethod }\end{array}$ & $\left.\begin{array}{l}+ \\
+\end{array}\right\}$ Syphilis \\
\hline $\begin{array}{l}\text { FTA-ABS } \\
\text { TPHA macromethod }\end{array}$ & $\begin{array}{l}\text { - Biological false positive results } \\
\lambda \text { or early syphilis or old syphilis }\end{array}$ \\
\hline $\begin{array}{l}\text { FTA-ABS } \\
\text { TPHA macromethod }\end{array}$ & $\begin{array}{l}\text { + Possible technical error in } \\
\text { one of the reactions }\end{array}$ \\
\hline
\end{tabular}

Fig. 2 Scheme for serological testing in subjects with suspected syphilis 


\section{References}

Alessi, E., Cainelli, T., and Scioccati, L. (1973). La reazione di emoggalutinazione (TPHA) nella sierodiagnosi della sifilide. Giornale italiano di dermatologia minerva dermatologica, 108, 387-395.

Alessi, E., and Scioccati, L. (1977). Test di emoagglutinazione treponemica (TPHA). Validità del micrometodo eseguito con le diluizioni dei sieri 1/20-1/40. Bollettino dell'Istituto sieroterapico milanese, 56, 102-107.

Coffey, E. M., Bradford, L. L., Naritomi, L. S., and Wood, R. M. (1972). Evaluation of the qualitative and automated quantitative microhemagglutination assay for antibodies to Treponema pallidum. Applied Microbiology, 24, 26-30.

Cox, P. M., Logan, L. C., and Norins, L. C. (1969). Automated quantitative microhemagglutination assay for Treponema pallidum antibodies. Applied Microbiology, 18, 485-489.

Garner, M. F., Backhouse, J. L., Daskalopoulos, G., and Walsh, J. L. (1972). Treponema pallidum haemagglutination test for syphilis. Comparison with the TPI and FTA-ABS tests. British Journal of Venereal Diseases, 48, 470-473.
Garner, M. F., Backhouse, J. L., Daskalopoulos, C., and Walsh, J. L. (1973). The Treponema pallidum haemagglutination (TPHA) test in biological false positive and leprosy sera. Journal of Clinical Pathology, 26, 258-260.

Johnston, N. A. (1972). Treponema pallidum haemagglutination test for syphilis. Evaluation of a modified micro-method. British Journal of Venereal Diseases, 48, 474-478.

Luger, A., and Spendlingwimmer, I. (1973). Appraisal of the Treponema pallidum haemagglutination test. British Journal of Venereal Diseases, 49, 181-182.

O'Neill, P. (1976). A new look at the serology of treponemal disease. British Journal of Venereal Diseases, 52, 296-299.

Rathlev, T. (1967). Haemagglutination test utilising pathogenic Treponema pallidum for the serodiagnosis of syphilis. British Journal of Venereal Diseases, 43, 181-185.

Tringali, G. (1970). Haemagglutination test utilising pathogenic Treponema pallidum (TPHA) in comparison with other serologic tests for syphilis. Annali Sclavo, 12, 311-320.

Young, H., Henrichsen, C., and Robertson, D. H. H. (1974). Treponema pallidum haemagglutination test as a screening procedure for the diagnosis of syphilis. British Journal of Venereal Diseases, 50, 341-346. 